\title{
A VERDADEIRA FILOSOFIA PARA DESCARTES EM “CARTA PREFÁCIO DOS PRINCÍPIOS DA FILOSOFIA"
}

\section{THE TRUE PILOSHOPY DESCARTES LETTER PREFACE TO THE PRINCIPLES OF PHILOSOPHY}

\begin{abstract}
DIRCEU FERNANDES DOS SANTOS JUNIOR
Mestrado em Direito em andamento (Pontifícia Universidade Católica de São Paulo - PUC SP); Especialização em Direito Penal e Processo Penal (Universidade Presbiteriana Mackenzie - 2005-2006); Especialização em Direito

Processual Penal (Universidade São Francisco - 1999-2000); Bacharel em Direito (Universidade Presbiteriana Mackenzie 1993-1997); Graduado em Engenharia Elétrica (Pontifícia Universidade Católica de São Paulo - PUC SP).
\end{abstract}

dirceufernandes@uol.com.br

\section{RESUMO}

O presente artigo tem por objetivos discorrer sobre a Verdadeira Filosofia tendo como base a Carta-Prefácio dos Princípios da Filosofia e seus ensinamentos. Serão abordadas as questões da educação, seu desenvolvimento comportamental tendo na filosofia a base da utilidade às pessoas e à vida e não mais como comportamento repetitivo remanescente da Idade Média. Contraposição à Filosofia do Ser, inspirada na Fé e tomada pela Teologia platônico-agostiniana dependente apenas de iluminação Divina. A existência de Deus, as verdades e a consciência pautadas pela Moral provisória. Conclusões condicionadas na base do racionalismo de uma filosofia acessível a todos.

Palavras-chave: educação; filosofia; fé; moral; ser.

\begin{abstract}
This article aims to discuss the True Philosophy based on the Letter-Preface of the Principles of Philosophy and teachings. Education issues will be addressed, taking their behavioral development philosophy based utility to people and life and not as repetitive behavior reminiscent of the Middle Ages, opposed to Philosophy of Being, Inspirational Faith and taken by the Platonic-Augustinian Theology dependent only on Divine illumination. The existence of God the truth and conscience guided by Moral provisional. In conclusions conditioned on the basis of rationalism in an accessible philosophy at all.
\end{abstract}

Keywords: being; education; faith; moral; philosophy.

\section{SUMÁRIO}

INTRODUÇAO; 1. A EDUCAÇÃO E SEUS ENSINAMENTOS; 1.1 Desenvolvimentos que comportam a Razão; 1.2. O uso da Razão; 2. AS GRANDES QUESTÕES DA FILOSOFIA; 2.1. Princípios de Filosofia e a existência de Deus; 2.2. Verdades; 2.3. Consciência; 3. A ÁRVORE DA FILOSOFIA; 3. 1. A Moral; 3.2. A Moral Provisória; CONCLUSÃO; REFERÊNCIAS. 


\section{INTRODUÇÃO}

Descartes inaugurou o pensamento moderno. Foi assim uma das figuras-chave na Revolução Científica do Século XVII e do pensamento filosófico Moderno. Pensador, filósofo, físico e matemático francês. Nasceu em La Haye em Touraine no dia 31 de março de 1596, falecendo em Estocolmo em 11 de fevereiro de $1650^{1}$.

Graduou-se em direito, em 1616, pela Universidade de Poitiers. Ficou conhecido por seu nome latino "Renatus Cartesius". Seguiu carreira militar (Holanda) onde ingressou nos exércitos de Maurício de Nassau. Em seus estudos, foi influenciado por Platão, Pitágoras, Aristóteles, Santo Agostinho, São Tomás de Aquino e Montaigne.

Em sua “Carta-Prefácio dos Princípios da Filosofia” as questões da educação, teve seu desenvolvimento como a base filosófica a utilidade às pessoas e à vida e não mais como comportamento repetitivo remanescente da Idade Média. Em contraposição à Filosofia do Ser, inspirada na Fé e tomada pela Teologia platônico-agostiniana dependente apenas de iluminação Divina infere-se sobre a existência de Deus, as verdades e a consciência pautadas pela Moral provisória.

\section{A EDUCAÇÃO E SEUS ENSINAMENTOS}

Para Descartes, a educação contentava-se até então com a repetição de ensinamentos, principalmente àqueles pregados durante a toda a Idade Média. Em seu pensamento, a ciência e a filosofia estavam esclerosadas e estabeleciam à época como ponto de partida a filosofia escolástica de cunho tomista-aristotélico onde as coisas estavam ligadas à tentativa de conciliar o aristotelismo com o cristianismo, uma verdadeira adequação aos textos bíblicos, gerando uma filosofia do Ser, inspirada na fé com a teologia científica. O pensamento até então, era visto como platônico agostiniano em nome do racionalismo aristotélico.

1 COLEÇÃO "OS PENSADORES". Discurso do Método; As Paixões da Alma; Meditações; Objeções e Respostas. São Paulo: Nova Cultural. 1996. p.5-23. 
A concepção platônico-agostiniana pregava que o conhecimento dependia de uma particular iluminação Divina. O espírito humano estava ligado diretamente ao ininteligível, opondo São Tomás de Aquino a gnosiologia empírica aristotélica limitando o conhecimento humano ao sensível e à dependência do Divino. A alma era considerada como um ser autônomo e a materialidade do corpo, por sua vez, era assim compreendida como um obstáculo do que um instrumento da verdade. O “agostinianismo" pregava a primazia da vontade sobre o intelecto. Já, os tomistas pregavam a primazia do intelecto sobre a vontade, a ordem sobrenatural e a essência Divina.

\subsection{Desenvolvimento que comporta a Razão}

A Razão independente da experiência sensível, sendo inata, imutável, estaria presente em todos os homens, em todas as relações humanas de forma que a fé não deveria interferir nessas relações e que deveria ficar guardada com cada um, não invadindo as esferas da política, filosofia e das ciências em geral.

Moderno, Descartes defendia a ideia de que a razão deveria permear todos os domínios da vida humana, pois seria voltada contra as mais diversas formas de dogmatismos, préconceitos, pré-conhecimentos de caráter religioso ou tomista-aristotélicos.

\section{AS GRANDES QUESTÕES DA FILOSOFIA}

A Filosofia à época de Descartes debruçava-se em grandes questões, tais como Deus, Imortalidade da alma (separação desta com o corpo). Nesse aspecto, poderia o pensamento existir sem o corpo?

Para Descartes, a mente, o espírito, a alma e a Razão seriam palavras de mesma significação. A alma superaria a uma existência fora daquela contida na esfera do corpo. A Razão não admitiria limites e nada mais seria considerado como sagrado a partir dos questionamentos e dúvidas.

O homem passaria, então, a pensar em sua condição existencial de dúvidas inatas e ter consciência individual e não mais religiosa. 


\subsection{Princípios da Filosofia e a existência de Deus}

Em seu "Princípios de Filosofia", Descartes visou tornar sua filosofia um manual a ser utilizado por todos, um texto redigido para filósofos iniciantes. Preocupado com seu sucesso pessoal no mundo, idealizou uma filosofia sistematizada e acessível para um grande público.

0 pensamento cartesiano estava voltado para a utilidade da filosofia às pessoas e à vida, tendo como ponto de partida ser a filosofia inquestionável. Para ele, até as verdades matemáticas poderiam nos enganar, pois poderiam ser ilusões criadas por demônios com o objetivo de levar-nos ao erro no agir e no pensar.

Deveríamos gerar a dúvida de modo que enquanto não poderíamos duvidar que estivéssemos duvidando, seríamos algo que duvida de algo, algo pensante na dúvida, e consequentemente algo que existe por pensar e, portanto: penso, logo existo.

Dessa forma, nosso pensamento seria imperfeito, e criado por um Deus perfeito.

Em Meditações metafísicas, outra grande obra escrita em latim, escolheu como interlocutores a parte mais "letrada" da sociedade, aquela que se mostraria mais refratária às suas ideias. Para ser admitida nos meios escolares, universitários e religiosos, era fundamental que sua filosofia pudesse ser aceita nesse meio. Ademais, o desenvolvimento da ciência também dependia dessa aprovação. Neste livro, ele vai se defrontar com as grandes questões da Filosofia primeira, aplicando seu método ao conhecimento de Deus e à demonstração da imortalidade da alma, mediante a separação da existência desta como diferente da do corpo. Se o pensamento é uma propriedade essencial da alma, enquanto a extensão é do corpo, então um pode existir sem o outro.

A demonstração cartesiana é eminentemente lógica, procedendo-se passo a passo, de tal maneira que uma propriedade, o pensamento, é demonstrada como exclusiva da alma. Para ele a mente, espírito, alma e razão são palavras de mesma significação. Segue-se, então, um tipo de existência distinta daquela que se oriunda do corpo, uma forma de existência das ideias e dos pensamentos. O corpo, por sua vez, será conhecido pela extensão, sendo que essa propriedade não poderá ser aplicada à alma. Logo, segue-se a outro tipo de existência, o que conhecemos comumente como material. Nesta obra, aprofunda as suas provas da existência de Deus, tornando o ser divino uma ideia que pode ser explorada racionalmente. E quando dizemos prova racional da existência de Deus, insistimos no termo racional, pois ela independe da fé que 
um indivíduo possa ou não ter. Basta que ele ponha a sua razão a funcionar para alcançar a mesma conclusão.

Até um ateu pode, então, provar a existência de Deus. A contrapartida dessa formulação é que a razão começa a entrar no terreno exclusivo da teologia, em particular de uma teologia revelada ou dogmática. A razão já não admite limites, senão aqueles que ela mesma se dá. Essa disciplina chamar-se-á Teologia natural ou Filosofia primeira. Os objetos da religião, as crenças e os dogmas, e os princípios teológicos serão submetidos a uma avaliação racional.

\subsection{Verdades}

A demonstração lógica do cartesianismo a respeito das verdades, parte da premissa que nossas ideias são inatas e que representadas por formas, movimentos, e tamanhos entendidos através da geometria são deduzidas apenas racionalmente e essas ideias seriam um fim em si mesmas.

Nossos pensamentos intuitivos não deveriam gerar dúvidas, uma vez que provada a existência de Deus.

Em Carta-Prefácio, as verdades eram conhecidas, mas mal exploradas. Descartes soube fazer algo novo com o antigo, o "imutável”, atingindo a verdade com sabedoria, utilidade, unindo a teoria (saber verdadeiro) com a prática (através de aplicações concretas: aqui a física, a matemática).

Os Princípios verdadeiros, seriam indubitáveis epistemologicamente bem como auto suficientes e consequentemente não depender de um outro conhecimento. O Princípio seria o começo e por dedução lógica atingiria outros conhecimentos que dependeriam dele. 0 cogito não seria abalado por nada. Seria a primeira verdade, à prova de dúvidas.

A verdade derivaria do fato de que todos os homens possuiriam capacidades intelectuais e sementes de verdades que permitiriam (re)descobri-las por pouco esforço seguindo regras e procedimentos adequados. A verdade não teria história e poderia ser obscurecida pelos conceitos dos maus filósofos depois de perdida ao longo do discurso submetido à lógica da catástrofe que governaria o pensamento. 


\subsection{Consciência}

Para Descartes, a mente, o espírito, a alma e razão são palavras de mesma significação.

Segue-se, então, um tipo de existência distinta daquela que se oriunda do corpo, uma forma de existência das ideias e dos pensamentos. O corpo, por sua vez, será conhecido pela extensão, sendo que essa propriedade não poderá ser aplicada à alma. Logo, segue-se a outro tipo de existência, o que conhecemos comumente como material. Aprofunda as suas provas da existência de Deus, tornando o ser divino uma ideia que pode ser explorada racionalmente. A nossa consciência individual é separada do corpo e continua a existir mesmo sem o corpo. A chamada glândula pineal seria a sede da nossa alma.

Dessa forma, a alma buscaria o conhecimento da verdade e o corpo seria o responsável pelas sensações.

\section{A ÁRVORE DA FILOSOFIA}

A Árvore da Filosofia seria composta por suas raízes - a Metafísica, o tronco, a física e os galhos que saem do tronco seria todas as demais ciências. E, "Exibindo um saber com ordem e indicando o caminho que é preciso percorrer para constituí-lo, a árvore cartesiana oferece uma representação ideal da filosofia e da atividade filosófica"². Ainda:

Primeiramente, um homem que ainda não tem mais do que o conhecimento vulgar e imperfeito [...] deve antes de tudo buscar formar-se uma moral que possa bastar para regrar as suas ações de sua vida, no intuito de não sofrerem retardo, e devemos, sobretudo, tratar de viver bem ${ }^{3}$.

Nesse sentido, podermos afirmar que o pensamento cartesiano afirmou que todos os homens disponibilizariam da razão e do bom senso, de uma capacidade de bem pensar e julgar, não bastando ter o espírito bom, mas o principal seria aplicá-lo bem.

Donde a necessidade de aplicar e estudar a lógica, não a formalista que utilizada pelas “escolas" escolásticas, mas sim pelo espírito que a conduziria bem.

Sua operação fundadora é a chamada "dúvida" radical ou hiperbólica, que é um momento de provação intelectual: ela leva às portas da loucura, fazendo do

\footnotetext{
${ }^{2}$ DESCARTES, René. Carta-Prefácio dos Princípios da Filosofia. São Paulo: Editora Martins Fontes. 2003. pág. XXIII.

${ }^{3}$ DESCARTES, René. Op. Cit. pág. 23.
} 
mundo e de meus pensamentos os joguetes de um Enganador onipotente. Ademais, uma vez passada e sobrepujada a prova da dúvida, a metafísica não é uma disciplina fácil. Seus objetos - Deus, a alma, as primeiras noções que estão em nós - têm em comum a imaterialidade e por consequência são percebidos só pelo intelecto puro" ${ }^{4}$.

A Metafísica apresenta-se como o saber imaterial. Não há física sem metafísica. Descartes quis dar aos primeiros princípios do conhecimento uma certeza absoluta e fazer da metafísica uma ciência mais clara e certa do que as anteriormente propostas pelos geômetras e tomistas-aristotélicos. Seria, portanto, preciso provar a existência de Deus e a natureza imaterial do nosso espírito, substância pensante.

Filosofar consistiria em percorrer a Metafísica agindo sobre o mundo, sobre as ciências, manter nosso corpo em bom estado e responder à questão: “o que fazer ?”.

A Árvore da Filosofia seria composta pela seguinte formação estrutural: As raízes seriam a Metafísica, o tronco seria a física e os galhos que saem desse tronco seriam todas as outras ciências. Dessa forma, o saber humano seria essencialmente uno, tendo ordem, unidade e sistematicidade do saber, tudo bem separado do pensamento teológico e aristotélico-tomista uma vez que conforme aponta José Antônio Tobias, filósofo da Pontifícia Universidade Católica de São Paulo na década de 60: “Na Ciência Sagrada” diz São Tomás de Aquino, todas as coisas são tratadas sob o ponto de vista de Deus" ${ }^{5}$.

E, dessa forma a Razão Teológica seria aquela estudada sob o ponto de vista da Fé, de Deus. A Filosofia é "A Ciência das causas supremas do ente, conhecidas pela luz natural da razão"6.

E segundo Aristóteles: "a filosofia seria a ciência do ente enquanto ente"7.

Para Aristóteles, o homem é animal político (zoôn politikon). E a razão é a faculdade que todo homem possui de julgar. Para Descartes, ele é, essencialmente, um animal racional. No início de seu Discurso sobre o Método, ele afirma a igualdade, de direito, do bom senso ou razão: todos nós possuímos a razão, ou seja, essa capacidade de bem julgar e discernir o verdadeiro do falso. Nem todos os homens, porém, utilizam corretamente sua razão"8.

\footnotetext{
${ }^{4}$ Idem. pág. 25.

${ }^{5}$ TOBIAS, José Antônio. Filosofia do Direito. São Paulo: JH Mizuno. 2013, p. 33.

${ }^{6}$ TOBIAS, José Antônio. Op. Cit. p. 33.

7 TOBIAS, José Antônio. Idem. Pág. 33 apud Aristóteles. Metaphysica. In: latine. Paris: Firmin Didot, 1927. V. II, Liber III, capitulus I, p. 500.

${ }^{8}$ REZENDE, Antônio. Curso de Filosofia. $5^{a}$ ed.. Rio de Janeiro. Jorge Zahar. 1992. p.87, 88.
} 
A Teologia seria a ciência das causas supremas do ente e iluminada pela fé segundo o raciocínio tomista. $\mathrm{E}$, nesse aspecto, Descartes respondeu que a tarefa do Filósofo não seria determinar o mais difícil a pensar, analisar as coisas pela Fé, mas sim pelo o descobrimento da utilidade para viver a vida e a filosofia, pois a árvores cartesiana oferece uma representação da filosofia e sua respectiva atividade epistêmica. 0 pensamento cartesiano foi um pensamento extremo e fundador e o saber dependeria de uma série de questionamentos que ligados à metafísica tal como o definia:

\begin{abstract}
"Acaso Deus existe, ele é ou não enganador ? O que sou eu, eu que quero saber? 0 que penso e como?...Como pensar bem a natureza se não sabemos o que somos, nós que a pensamos, e se não sabemos que é Deus que a criou?"’
\end{abstract}

\title{
3.1 A Moral
}

Em Princípios da Filosofia, Descartes expôs inicialmente a monotonia à respeito dos escritos para a Filosofia e sua evolução inicialmente em Carta a Mersenne:

\begin{abstract}
Estou com vontade de reler um pouco a Filosofia deles [dos jesuítas], o que não faço há vinte anos, a fim de ver se me parecerá agora melhor que outrora. E, para tanto, peço que me informeis os nomes dos autores que escreveram cursos de Filosofia e que são os mais seguidos por eles e se eles têm alguns novos depois de vinte anos; lembro-me apenas dos Conimbricences, Toledo e Rúbio. Gostaria de saber se há alguém que tenha feito um compêndio de toda a Filosofia da Escola, e que seja seguido, pois isso me pouparia tempo de ler os grossos livros deles. Havia, parece-me, um Cartuxo ou Folhante que o fizera, mas não lembrome mais seu nome" ${ }^{10}$.
\end{abstract}

Os Principia, instrumento de combate direcionado a exposição e ao conjunto da Filosofia, um manual de apoio destinado a servir nas escolas composto de artigos curtos e densos, foram instrumentos de destinados a fazer triunfar o cartesianismo nos meios intelectuais e mandar para o museu das curiosidades fora de uso as "filosofias" que o precederam como se depreende do texto acima.

No entanto, três anos após a publicação dos Principia, o início da Carta-prefácio de 1647 testemunhou certa amargura, pois asseverava que a obra não havia sido "bem entendida". Os manuais escolásticos continuavam em vigor sendo que os jesuítas cartesianos eram raros e vez ou outra iniciados à nova filosofia.

\footnotetext{
${ }^{9}$ DESCARTES, René. Op. Cit. p. 28.

${ }^{10}$ DESCARTES, René. Idem. Cit. p. 33.
} 
Principes de la Philosophie, foi acompanhado da importante Lettre-Preface como texto de combate do começo ao fim dirigido contra a "filosofia da escola", um manifesto explicativo complementar aos elementos dos dez anos da Obra “Discurso do Método", bem como texto dirigido para filósofos iniciantes no estudo da Razão.

Os Filósofos não foram capazes em dois mil anos de atividade de determinar um único enunciado incontestável e perdiam seu tempo em disputas estéreis.

Segundo Descartes e seu racionalismo, Platão havia dado origem aos Céticos. Aristóteles aos empiristas ingênuos e seus seguidores incorreram em discussões e a erros extravagantes. Na pior hipótese, eram levados a heresias e dissensões que afligiam o mundo até então. A Razão veio a acrescentar um novo episódio à longa e deplorável história dos fracassos filosóficos como crítica aos que os precederam.

A Filosofia inteira estava para ser refeita e a lógica da catástrofe governava o pensamento pela fé apenas. Cometeram um erro da tradição sem renovação.

Em Carta Prefácio as verdades conhecidas até então eram mal explicadas e mal exploradas. Para Descartes a sabedoria era a união entre a teoria e a prática onde a fé deveria ser colocada à sua margem. A teoria - o saber verdadeiro e a prática as ações concretas o que levaria à utilidade.

Os Principias seriam indubitáveis epistemologicamente e auto suficientes, não dependendo de um outro conhecimento, pois princípio para ele era o começo, o início e por dedução atingir-se-iam outros conhecimentos que dependeriam dele.

Assim, o cogito não seria abalado por nada uma vez que seria a primeira verdade à prova de dúvida, verdades fundantes.

\subsection{A Moral Provisória}

Na Árvore da Filosofia, a Moral seria o último grau da sabedoria. Mas, a mais alta e perfeita Moral.

O domínio do saber que estudaria os princípios e regras e que responderia à questão: “que fazer?”

Deveríamos ajustar nosso espírito a conhecer somente certezas, mas o que deveríamos fazer enquanto não possuidor dessa perfeita Moral? 
Resposta: Viver bem. Primeiro viver bem e depois filosofar. Filosofaríamos paciência, prudência. Mas, a Moral provisória estaria ultrapassada quando do atingimento da mais alta e perfeita moral situada no mais alto ponto da Árvore. Em Princípios da Filosofia, Descartes expôs somente as raízes metafísica e o tronco.

Dessa forma, a questão moral e suas verdades metafísicas teriam consequências éticas, pois Descartes afirmou que a Moral não era um galho como os outros, pois nunca como filósofos estaríamos certos do que fazer ou o que seria correto fazer, daí a Moral Provisória pois sua passagem da obscuridade à clareza.

A Moral imperfeita poderia ser seguida provisoriamente enquanto não adquirida uma Moral Perfeita, pois essa partiria do pressuposto d conhecimento das outras ciências e seria o ápice da sabedoria.

A Moral Provisória consistia apenas em três ou quatro máximas que expôs: A primeira seria obedecer às leis e aos costumes afastando-se dos excessos. A segunda máxima seria a tomada de uma atitude firme e resoluta e não seguir opiniões mais duvidosas, mas sim as mais prováveis. A terceira seria vencer a mim mesmo do que o curso dos acontecimentos e meus desejos antes da ordem do mundo.

No entanto, permanece obscura a intenção política de Descartes no Discurso sem ao menos um breve esclarecimento das três principais características de sua retórica. Acreditase, muitas vezes, que Descartes seja um conformista político, pois sua moral provisória começa assim “A primeira [regra] foi obedecer às leis e costumes de meu país, mantendo sempre a religião em que Deus me deu a graça de ser instruído desde a infância". ${ }^{11}$

Por fim, a conclusão dessa Moral Provisória buscaria uma adaptação das ocupações mundanas da vida para sim escolher as melhores ocupações, e empregar a vida em cultivar a razão como progresso para o encontro da instrução em função de Deus ter-nos concedido a discernir o verdadeiro do falso e a atingir os fundamentos de alguma filosofia mais certa que a vulgar tendo a necessidade de sermos resolutos em nossas ações.

Do geral e do exposto à respeito da moral provisória cartesiana exsurgem algumas Sentenças tais como: "Penso, logo existo", "O bom senso é a coisa mais bem dividida no mundo: todos pensam ter em abundância”, “Além do nosso pensamento, nada está realmente sobre nosso controle”, “Conquiste você mesmo, não o mundo", “A dúvida é a origem da sabedoria”,

${ }^{11}$ STRAUSS, Leo. História da Filosofia Política. Rio de Janeiro: Forense Universitária. 2013. p. 382. 
"Nada vem do nada" e "As melhores mentes podem ter as maiores virtudes ou os maiores vícios" ${ }^{\prime 2}$.

\section{CONCLUSÃO}

Descartes desenvolveu um novo método, qual seja: O domínio e a concepção da natureza como ela é e sempre assim será, imutável conceitualmente, lançando as bases para um mundo mais útil e questionável.

A Ciência Moral, maior e mais perfeita, o mais alto grau da sabedoria da árvore filosófica, o último grau da sabedoria, tratou primeiro da alma humana e logo após de Deus. Descreveu sua filosofia e a sua meta a Moral perfeita como suprema, desenvolvendo todo um raciocínio crítico que levou a assertiva de utilidade à vida contrapondo toda a filosofia antiga baseada na fé, pois a criatividade humana estaria mais propensa ao conhecimento e sua utilidade.

Segundo Descartes, a Moral provisória teria como primeira regra obedecer às leis e costumes e manter sempre a religião dada por Deus.

Para ele, todos os homens desejam o conhecimento por natureza e para tanto deveriam construir um método e não apenas a razão natural até então conhecida. A matemática tomada como modelo nada deve aos sentidos e ao corpo, exigindo, pois, a extinção geral de toda e qualquer opinião sem base matemática.

Dessa forma, Descartes lançou outro propósito além de alcançar em sua Obra Principia a um amplo público, antes de Kant, propôs o uso público da razão, para todos.

Sua preocupação central residia no como atingiríamos o conhecimento e como poderíamos ter acesso a ideias verdadeiras, que fossem imunes ao erro, desde que questionadas e quando perseguidas segundo um procedimento metódico, sistemático.

Era um pensamento jovem, aberto à crítica e aos questionamentos, e capaz de exercer uma dúvida cética e de resistir à mesma dúvida graças a uma razão aberta aos seus próprios princípios.

${ }^{12}$ SÓ FILOSOFIA. Disponível em: <http://www.filosofia.com.br/historia_show.php?id=70> Acesso em: 9 abr. 2014. 
Ele lutava, portanto, por um mundo onde a fé não ordenasse as relações humanas, mas ficasse confinada a um lugar específico, ao do culto de cada um, não invadindo as esferas dos costumes, da política, da filosofia e da ciência em geral. Moderno, ele defendia a ideia de que a razão deveria permear todos os domínios da vida humana, numa atividade libertadora, pois voltada contra as mais diversas formas de dogmatismo.

Ademais, o desenvolvimento de sua nova ciência (filosófica) defrontou-se com as grandes questões da Filosofia primeira, aplicando seu método ao conhecimento de Deus e à demonstração da imortalidade da alma, mediante a separação da existência desta como diferente da do corpo. Se o pensamento é uma propriedade essencial da alma, enquanto a extensão é do corpo, então um pode existir sem o outro.

Sua demonstração é eminentemente lógica, procedendo-se passo a passo, de tal maneira que uma propriedade, o pensamento, é demonstrada como exclusiva da alma. Para ele, mente, espírito, alma e razão são palavras de mesma significação. Segue-se, então, um tipo de existência distinta daquela que se oriunda do corpo, uma forma de existência das ideias e dos pensamentos. 0 corpo, por sua vez, será conhecido pela extensão, sendo que essa propriedade não poderá ser aplicada à alma.

Logo, segue-se a outro tipo de existência, o que conhecemos comumente como material. Nesta obra, aprofunda as suas provas da existência de Deus, tornando o ser Divino uma ideia que pode ser explorada racionalmente. E quando dizemos prova racional da existência de Deus, insistamos no termo racional, pois ela independe da fé que um indivíduo possa ou não ter. Basta que ele ponha a sua razão a funcionar para alcançar a mesma conclusão. Até um ateu pode, então, provar a existência de Deus. A contrapartida dessa formulação é que a razão começa a entrar no terreno exclusivo da teologia, em particular de uma teologia revelada ou dogmática de cunho tomista. A razão já não admite limites, senão aqueles que ela mesma se dá ao seu inteiro critério de investigação empírica. Essa disciplina chamar-se-á Teologia natural ou Filosofia primeira. Os objetos da religião, as crenças e os dogmas, e os princípios teológicos serão submetidos a uma avaliação racional. Nada mais será, doravante, considerado como sagrado, proveniente apenas e tão somente da religiosidade até então imposta. A razão não conhece mais limites e se aventura, inclusive, a conhecer a essência de Deus. A desmedida da razão constituirá doravante o cotidiano da filosofia, da ciência e de uma nova forma de sociedade.

As objeções e respostas possibilitaram uma discussão ampla e enriquecedora do texto cartesiano onde vale o confronto das ideias. 
Suas posições teológicas não foram, recebidas de forma receptiva, pois a razão entrava, mais profundamente, na análise de enlaces religiosos como a criação do mundo segundo a Bíblia. 0 desagrado da Igreja católica foi grande.

Seu método composto de quatro regras básicas: verificar, analisar, sintetizar e enumerar mantive coesas todas as verificações e desenvolvimentos e se existiam evidências reais e indubitáveis acerca do fenômeno ou coisa estudada, já não havia mais.

Com relação a sua Ciência, desenvolveu uma filosofia que influenciou muitos, até ser superada pela metodologia de Newton - Empirismo. Dividia a realidade em res cogitans (consciência, mente) e res extensa (matéria).

A teoria de Descartes forneceu a base para o cálculo de Newton e Leibniz, e então, para muito da matemática moderna.

Assim, falar em Racionalismo é certamente falar sobre um novo pensamento com base na Ciência, na Metodologia do pensar, na Razão. É uma linha de pensamento filosófica em que a razão é a única a proporcionar o conhecimento que mais adeque-se às realidades dos conceitos.

Nesse contexto, Descartes o legítimo representante do Racionalismo, do pensamento filosófico moderno fez desmoronar o sistema aristotélico-tomista de base geocentrista. Descartes trabalhou essa nova maneira de pensar: 0 questionamento, a dúvida. Duvidou de todo o conhecimento até então imposto, mas sem ser cético, sem atacar a dúvida pela dúvida cega, criou um Método partindo do princípio metafísico que algumas verdades são inquestionáveis, são transcendentais.

Os racionalistas acreditavam em conhecimentos anteriores, indiscutíveis, a priori, anterior à experiência, como por exemplo, o Princípio da Não contradição: "Ser não pode ser o Não-Ser". Em seu raciocínio (racionalista) criou a Árvore do Conhecimento tendo, pois a metafísica (além da física, da matéria) como sendo a base das outras ciências e, portanto, sustentando-as. Para ele, os questionamentos do que seria a realidade, do que seria natural ou sobrenatural e a física seria o tronco mecanicista do filósofo, fonte derivativa de todas as outras ciências, a mecânica, a medicina e a moral são explicadas tendo por base os corpos e seus movimentos.

Ocorreu a separação entre ciência e religião no pensamento cartesiano.

Suas regras tinham por objeto a razão dirigida ao bom caminho evitando-se o erro através da evidência (rejeita conhecimento dos sentidos), a divisão: divisão do estudo no maior 
número possível, a ordem que a problemas simples, chegam-nos os complexos, e a enumeração: revisão de todo o conhecimento garantindo o não esquecimento.

Em Carta-Prefácio dos Princípios da Filosofia, Descartes diz que é possível elaborar uma filosofia diferente. As verdades importantes: só Deus é perfeitamente sábio. Com relação à Filosofia, ela se estenda a tudo o que o espírito humano possa saber. E, o maior bem que um Estado pode ter são os filósofos muito ao contrário dos animais que procuram incessantemente alimentar-se, os homens devem procurar a filosofia - seu verdadeiro alimento. O bem supremo, a razão natural independe da fé e nada mais é do que o conhecimento da verdade devido às suas primeiras causas, a sabedoria estudada pela filosofia.

Descartes ao afirmar que os quatro graus da sabedoria contém: noções claras adquiridas pela sem meditação. Um segundo grau compreenderia o que a experiência dos sentidos traz-nos. O convívio com outros homens e seu ensinamento e a leitura de tudo aquilo que podemos aceitar como culturalmente correto e escrito por pessoas capazes. Dirigiu-se ao malogro de Platão e Aristóteles afirmando que este seguindo àquele foi menos franco, pois sendo discípulo de Platão não professou outros princípios senão os que já os possuía. Platão deu origem aos céticos. Aristóteles aos empiristas ingênuos, os sucessores desde então se consomem em discussões que levam na melhor das hipóteses, a "erros extravagantes", na pior, a "heresias e dissenções que afligem agora o mundo".

A filosofia inteira está para ser refeita. Objetos, então, seriam Deus, o espírito humano e todas as noções claras e simples que estão em nós. A Metafísica: representaria o saber do imaterial. Por que a metafísica estria na raiz ? Porque o cartesianismo é um pensamento que leva ao extremo a exigência e a radicalidade de um procedimento fundador. Metafísica tal como Descartes a define. 0 cartesiano definiu - a Razão pela utilidade.

\section{REFERÊNCIAS}

DESCARTES, René. Carta-Prefácio dos Princípios da Filosofia. São Paulo: Martins Fontes. 2003.

REZENDE, Antônio. Curso de Filosofia. $6^{\mathrm{a}}$ ed. Rio de Janeiro: Jorge Zahar,1992. 
ISSN 1981-3694

(DOI): $10.5902 / 1981369414287$

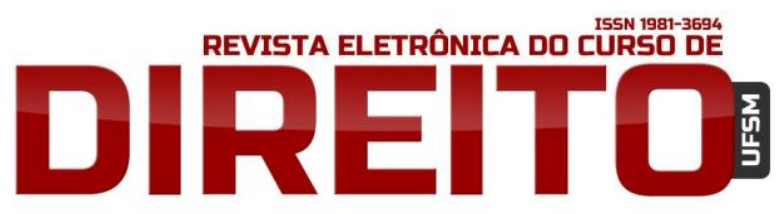

A VERDADEIRA FILOSOFIA PARA DESCARTES EM “CARTA PREFÁCIO DOS PRINCÍPIOS DA FILOSOFIA"

DIRCEU FERNANDES DOS SANTOS JÚNIOR

STRAUSS, Leo. História da Filosofia Política. Rio de Janeiro: Forense Universitária. 2013.

OS PENSADORES. Discurso do Método; As Paixões da Alma; Meditações; Objeções e Respostas. São Paulo: Nova Cultural. 1996.

TOBIAS, José Antônio. Filosofia do Direito. São Paulo: JH Mizuno. 2013.

SÓ FILOSOFIA. Disponível em: <http://www.filosofia.com.br/historia_show.php?id=70 >. Acesso em: 9 abr. 2014.

Recebido em: 08/06/2014 / Revisado em: 13/12/2014 Aprovado em: 14/12/2014 